Article

\title{
Urban Morphology and Qualitative Topology: Open Green Spaces in High-Rise Residential Developments
}

\author{
Efrat Eizenberg *, Orly Sasson and Mor Shilon \\ Faculty of Architecture and Town Planning, Technion-Israel Institute of Technology, Haifa 3200003, Israel; \\ E-Mails: efrate@technion.ac.il (E.E.), orlysa@campus.technion.ac.il (O.S.), mor.shilon@campus.technion.ac.il (M.S.) \\ * Corresponding author
}

Submitted: 16 June 2019 | Accepted: 21 August 2019 | Published: 21 November 2019

\begin{abstract}
High-rise housing complexes (HRHCs) are a prominent trend in urban development. They generate new configurations of open green spaces, thus creating a new set of human-environment relations and a new constellation of urban landscapes. However, little attention has been devoted by the literature to these new spatial configurations and the urban experience they offer. Focusing on the spaces between buildings, this research article examines the urban morphology of these large urban developments and how they are being experienced by residents. Based on morphological analysis, we propose a set of outputs with which to discern and evaluate various characteristics of these new spaces. Namely, a typology of HRHCS complexes, three evaluation indexes, and a green/gray nolli map. Drawing on morphological analysis, the research discusses the role of green spaces of HRHCs in the experience of residents. We portray different tensions arising from the residents' experience based on walking interviews and propose how these tensions are connected to the morphology of space. Juxtaposing the morphological and qualitative topological analyses, we focus on the way that different planning aspects of HRHCs' open spaces might foster everyday use and function as well as attitudes and feelings.
\end{abstract}

\section{Keywords}

high-rise housing; large urban developments; green open space; urban morphology

\section{Issue}

This article is part of the issue "Large Urban Developments and the Future of Cities" edited by Efrat Eizenberg (TechnionIsrael Institute of Technology, Israel).

(C) 2019 by the authors; licensee Cogitatio (Lisbon, Portugal). This article is licensed under a Creative Commons Attribution 4.0 International License (CC BY).

\section{Introduction}

Contemporary cities pose new challenges for urban planning and architecture as to the kind of spatial and social experiences they afford. Vertical urbanism-building much higher than ever before, or 3D urban growthhas become a dominant mode of urban development and redevelopment in many cities around the world. This mode of urban development also includes housing developments (Harris, 2015), though housing types are the outcome of the state's housing policy and, in many places, urbanization proceeds based on medium/lowrise and single-family housing developments (Winston, 2017). The volumetric cities that grow as a result offer a new design and functions based on technological in- novations and new planning cultures (Drozdz, Appert, \& Harris, 2018). Nevertheless, research in urban-related fields mostly generates horizontal analyses of urban realities; therefore, Graham and Hewitt (2012, p. 74) have emphasized the need for understanding the multiple meanings of volumetric urbanism and its effects on social, cultural, spatial, and political life in cities.

Unlike their affordable predecessors, contemporary high-rise housings are developed for middle- and upperincome populations and share some prominent characteristics (Brumann, 2012; Fincher, 2007). When developed as large urban developments, usually in the outskirts of cities or as part of new towns, they are usually developed in the form of high-rise housing complexes (HRHCs). In some places, such as Hong Kong, Singapore, 
and Israel, HRHCs have become the dominant form of development (Lowry \& McCann, 2011; Turkington, van Kempen, \& Wassenberg, 2004; Yuen \& Yeh, 2011). In Israel, for instance, in 1992, only $2 \%$ of new apartments were built as 10 to 20-story buildings, compared to 2012, when the rates climbed to more than 30\% (Aviv et al., 2018).

The open (green and gray) spaces of HRHCs receive little attention in the literature, although they in effect produce a distinct and divergent urban landscape for their residents. Moreover, given the magnitude and spread of HRHC developments, the form of HRHC open spaces and their encapsulated experience will presumably dominate the future urban landscape and, as a result, the general urban experience. Understanding them is thus crucial for envisioning the future of cities.

The literature on large urban developments in general and verticality in particular, suggests that topological analyses should be integrated into more common topographical accounts (Harker, 2014). This article follows the call to consider horizontal and vertical, topographical and topological aspects for explaining contemporary urban development of HRHCs. More specifically, the article juxtaposes the form of the open green spaces of HRHCs with the everyday topologies of HRHCs' inhabitants. Focusing on the spaces between buildings, we ask what the urban morphology of these large urban developments is and how they are being experienced by residents. In order to expand the understanding of the form, function, and experience of the open spaces of HRHCs, a morphological analysis is juxtaposed with a qualitative analysis.

The article is organized in four sections: First, it reviews the relevant literature on the meanings and functions of urban open space and urban morphology. Then, the methodology of combining morphological and qualitative topological analyses is presented. The findings demonstrate the use of urban morphology to characterize HRHCs, which are then juxtaposed with the qualitative analysis, producing an encompassing evaluation of the use, function, and experience of the open green spaces of HRHCs. The conclusion discusses the relations between new urban formations and the residents' experiences of them to produce long-term planning solutions that better meet users' needs and desires.

\section{Urban Open Space}

Research on urban open space is rich, well-grounded, and multifaceted (Kabisch, Qureshi, \& Haase, 2015). City planners have long grasped the importance of these green spaces and integrated them into the city in different shapes and forms to serve different agendas. Manicured nature in the form of parks and gardens in the urban fabric has been designed to promote recreation and people's well-being (Gandy, 2003).

The impacts of urban green space on people are well established in the literature and cover a wide range of implications (e.g., Hartig, 1993; Kaplan, 1995). The research focusing on the positive impacts of urban open green space covers health and recovery capacities, psychological well-being, and affectional capacities as a sense of belonging and caring, as well as cognitive processes, such as attention. All of these benefits are associated with exposure to green space and nature. These physical and psychological benefits to people's health and well-being are well demonstrated by research (Peters, Elands, \& Buijs, 2010; Soga \& Gaston, 2016).

Nevertheless, today, most of the world's population lives in biologically impoverished cities. People spend most of their time indoors with limited opportunities to interact with nature in their day-to-day life, and the human-nature interactions that occur are often restricted to green areas in open spaces (Lacoeuilhe, Prévot, \& Shwartz, 2017). Pyle (1978), who coined the phrase "extinction of experience," argues that the process of urbanization-which increasingly isolates humans from the experience of nature-is also one of the greatest causes of the biodiversity crisis. The extinction of experience, thus, is recognized as a major contemporary social and environmental issue (Miller, 2005; Soga \& Gaston, 2016). Cities are built for humans, and given the growing recognition of the importance of interacting with nature for people's lives-at least in Western societies-green infrastructures should be integrated into any form of urban development. Planning our cities with both people and nature in mind can align the agendas of public well-being and ecological benefits and make efficient use of urban open space (Shwartz, Pett, Irvine, Dallimer, \& Davies, 2016).

To benefit from social interactions in public spaces, physical settings that encourage and strengthen their occurrence are required (Kaplan, 1995). Creating good physical conditions in open spaces can prolong necessary activities (i.e., everyday tasks), create an inviting atmosphere for recreational activities, thus indirectly encouraging a broad spectrum of social activities (Gehl, 2011), and improve people's physical and psychological wellbeing (Jackson, 2003). Although open green spaces of HRHCs can benefit their users and produce a new and unique experience, the literature has yet to study these new urban forms. An exception is the work of Huang (2006), which ties the form of high-rise courtyards to residents' social interactions. However, a comprehensive view that portrays the morphology of open spaces created by HRHCs and provides a deeper insight into the qualities, observations, and practice that they offer to their users has yet to be found.

The urban landscape is abundant with forms and functions that are produced by planners' zoning and land uses, private and public divisions, and environmental and societal considerations. However, the urban landscape is also the result of multiple experiences, practices, and meanings created by users: "Urbanism exists only through the process of inhabiting the city, where inhabiting refers both to everyday forms of education of attention and to the mobile constitution of urbanism, 
which are the product of historical accretion and alignment" (McFarlane, 2011, p. 668). The different forms of the built environment are often instrumentally organized and evaluated as better or more sustainable than others and as more attractive than others for different functions and use (Jabareen, 2006). This study scrutinizes the urban morphology of green spaces in HRHCs and juxtaposes it with a qualitative topology of $\mathrm{HRHC}$ residents.

\section{Urban Morphology and HRHCs}

The well-established field of urban morphology dates back to the end of the 19th century and has since yielded various concepts and frameworks (Whitehand \& $\mathrm{Gu}, 2007)$. The focus on urban hierarchy structures the basic components of urban morphology as an enclave, a block, a superblock, and a neighborhood (Patricios, 2002) and their repeating arrangements establish a pattern. Pont and Haupt (2010) suggest four key territories for urban morphology: lot, island, fabric, and district. Rode, Keim, Robazza, Viejo, and Schofield (2014) suggest three fundamental physical elements of the urban form: buildings and their related open spaces, plots or lots, and streets. There are other examples as well. Regardless of its components, rather than producing mere categorical analytics of different city formations, the urban morphology of the built environment, as Kropf (2018) suggests, exposes the more complex relations among physical objects and people, layouts, urban ecologies, and processes at the practical level as well as concepts and thinking tools for urban analyses at the theoretical level. In this way, a multilevel understanding of the urban landscape and its uses, functions, and potential can be derived from a morphological analysis.

Hall and Sanders (2011) claim that there are some valuable (and generally well-established) qualities of urban design that are difficult to implement in large urban developments. They argue for the importance of urban morphology when facing challenges arising from urban planning and design, and especially for its importance regarding the planning of large-scale developments by emphasizing the persistence of the physical form over time - the loci of the morphology - in contrast with land use that shows little persistence. Moreover, urban morphology provides a "more precise language" and terminology that supports planning interventions and that is also "a contextual architectural language" that helps "integrate development into its surroundings" (Hall \& Sanders, 2011, p. 430). Finally, as exemplified by recent research (e.g., Hall \& Sanders, 2011; Rode et al., 2014), urban morphology can be used to compare different places, whether they differ in their planning regulations and culture or not.

The accelerated process of vertical urbanization in the last few decades is associated with economic and political processes such as neoliberalism. These processes are accompanied by the growing use of technology that enables higher towers to grow at faster rates than ever before (Nethercote, 2018). A major facet of contemporary volumetric cities is high-rise residential projects (Harris, 2015; Nethercote, 2018). Following these urban trends, scholars have begun to study the experience and use of different vertical residential projects in detail, as well as their constitution and assembly (see, e.g., Baxter, 2017; Harker, 2014). Understanding the morphology of this form of urban development may yield "a range of concepts and tools that articulate the different aspects and elements of urban form, the relations between them, and our role as the agents who create, use, and transform them" (Kropf, 2018, p. 9).

In Israel, contemporary housing and planning policy are closely related to the proliferation of volumetric urban forms (Aviv et al., 2018). Particularly, the development of HRHCs has become a recent trend with several common characteristics in terms of physical and social aspects: 1) HRHCs' residents are of relatively high socioeconomic status, which enables them to meet the high housing prices and maintenance cost (Alterman, 2010); 2) complexes are usually developed at once as a large urban development, by one or two entrepreneurs; and 3) regulations of minimal distances between high-rise buildings influence the size of the complex lot as well as the open space in the complex. By offering a morphological analysis of HRHCs that emphasizes the complexities of their open and green spaces, as well as people-setting relations, we hope to develop a mechanism for aggregating, representing, and analyzing the new and expanding patterns of large-scale and vertical urban landscapes.

\section{Methodology}

The research is based on five medium-size cities in Israel (with over 50,000 residents), wherein large-scale developments of high-rise housing in the last 15 years were common: Haifa, Hadera, Netanya, Petah Tikva, and Ashdod. This case study approach, which requires multiple sources for information and methods (Creswell, 1998), was chosen in order to discern common characteristics of HRHCs in Israel.

Large-scale, high-rise housing developments in these five cities were analyzed using plans, aerial photos, Google street view, and GIS. Within these large-scale developments, the complex was determined as the main component of the analysis, alongside the building and neighborhood. The demarcation of the complex in this research was based on Pont and Haupt's (2010) definition of the 'island component' of urban morphology. The island, just like the complex, is comprised of multiple contiguous private properties (lots) surrounded by public space. The combination of streets and a series of islands surrounded by streets constitute the urban fabric (Pont \& Haupt, 2010), which can also be referred to as 'a neighborhood.'

The complex comprises a distinguishable hierarchy of parts. Figure 1 details the subdivision of the complex unit into areas and their hierarchy. The built area of the com- 
plex contains the total layout of the buildings in the complex. The unbuilt area comprises a gray area and a green area. The gray area represents the surface area that is mostly used for parking, access roads and sidewalks; it is less accessible and useable and consumed by vehicles (Dovey \& Pafka, 2014). Green spaces in this research are defined as a coverage of planted vegetation and other elements that serve people for different functions and social activities (Gehl, 2011).

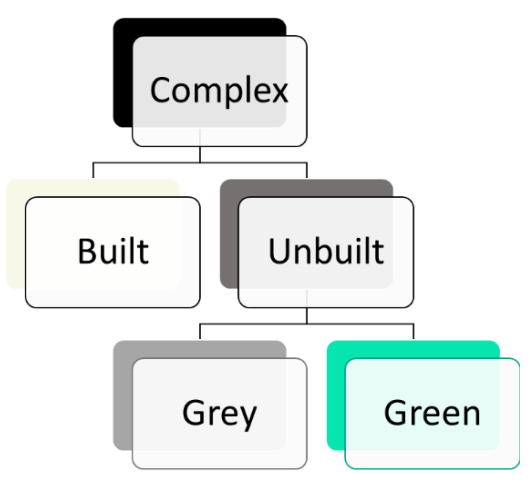

Figure 1. A hierarchy of areas in the complex.

Initial analysis of HRHCs in the five cities yielded $81 \mathrm{com}$ plexes for further morphological analysis. General variables were compiled for the morphological analysis, including the size of the complex, the size of the gray and green open areas in it, permeating areas, public and private areas, the number of buildings, the number of floors, the number of residential units, land uses, and more.

Integrating various research tools and approaches in planning research (Eizenberg \& Shilon, 2016), we juxtapose the morphological analysis with a qualitative analysis of users' experience and perceptions of the open space in HRHCs, based on observations and walkinginterviews (Evans \& Jones, 2011) with residents. A total of 16 residents from seven complexes, 2 to 3 residents from each complex were interviewed (in one complex in Netanya only 1 resident was interviewed). Eleven interviews were conducted in 4 complexes in PetachTikva and 5 interviews were conducted in 3 complexes in Netanya. Out of the 16 informants, 10 are women, and 6 are men. 5 are in their 30s, 8 are in their 40 s and 3 interviewees are more than 60 years of age.

The interviews were conducted while walking in the open spaces of the complex and lasted between 11.5 hours. The interviews were conducted in complexes that represent the two most dominant types of HRHCs in the study (as elaborated in the morphological analysis and Table 1) and with a green space area that is more than $1 / 5$ of the total area of the complex. We drew on snowball sampling to initiate a connection with informants. The interviews targeted different aspects of vertical lives in HRHCs, such as uses, functions, perceptions of HRHCs and social interactions in HRHCs, with a focus on the uses and experiences of the open green spaces.
Interviews were gathered to the point that stories and themes started repeating themselves.

\section{Morphological Analysis and Evaluation}

In line with the research question on how to discern HRHCs open space and users experience of these spaces, we draw on the morphological analysis of HRHCs in Israel to provide three innovative outputs: HRHCs' typology, three evaluation indexes, and a nuanced representation of HRHCs through green/gray nolli map. The following presents these outputs, how they were derived, and how they can be used in learning and evaluating the form of HRHCs. The next section will juxtapose these outputs with a qualitative analysis of HRHC users' experience based on walking interviews.

\subsection{A Typology of HRHCS}

A matrix of HRHC types was generated based on the general variable. As Figure 2 and Table 1 present, the produced matrix includes the general layout of the buildings in the complex (line or shape), the scale of the complex (small, medium, large) and 5 forms of gray-green organization. Based on this matrix, it is possible to suggest that the 'shape' form is clearly the dominant form of HRHCs, accounting for $77 \%$ of the complexes. In terms of scale, most complexes are small-scale (up to 4 buildings)$40 \%$ and medium-scale ( 5 to 9 buildings) $-38 \%$. Finally, type $\mathrm{C}-\mathrm{a}$ cluster of buildings surrounding an open green space-is the most frequent organization of gray-green in our sample (30\%), followed by type D (26\%)-a sort of a mirror image of type $C$, with a green area demarcating a cluster of buildings. Type $C$ was also the most flexible in terms of scale, accounting for $56 \%$ of the largescale HRHCs.

\subsection{Evaluation Indexes}

Three data-driven indexes were developed to create a grading method that can evaluate and compare the qualities of HRHCs: design variety, accessibility, and green-quality. Each index was calculated based on a combination of the form and function variables that were measured.

\subsubsection{The Variety Index (VI)}

The VI is calculated based on three parameters: height variety, design variety, and land-use variety. The height variety ( $v h$ ) is determined by counting the different building heights in the complex. The design variety (vd) is determined by counting different design styles of the complex buildings, and the land-use variety $(\mathrm{vl})$ is determined by the number of different land-uses in the complex (see Figure 3). To compare between complexes, vh and vd are calculated as a ratio of the number of buildings in the complex and are therefore represented by a ratio 


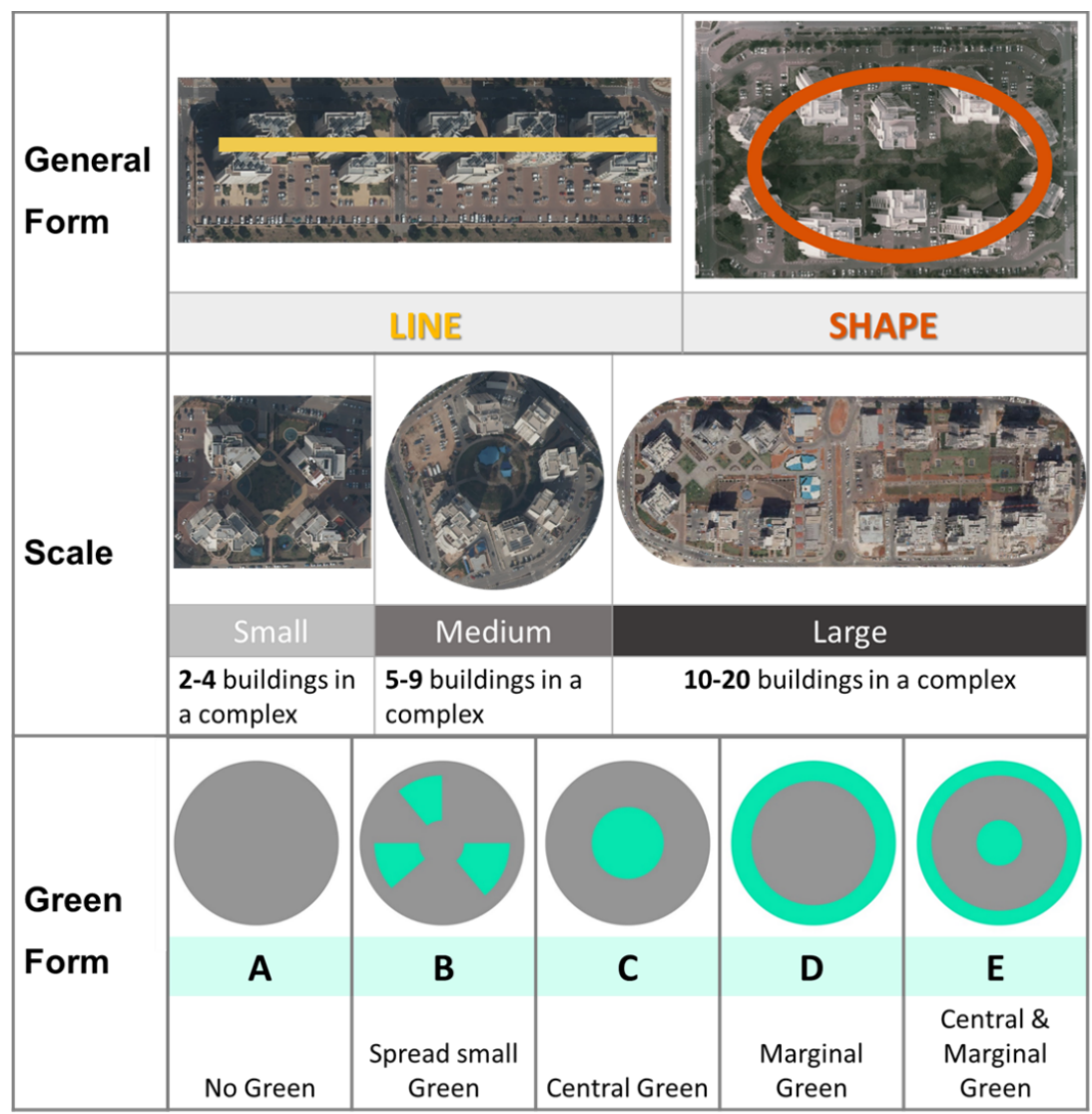

Figure 2. HRHCs morphological matrix scheme.

Table 1. The classification matrix of complexes.

\begin{tabular}{|c|c|c|c|c|c|c|c|}
\hline Green Form & A & B & C & D & $\mathbf{E}$ & sum & $\%$ \\
\hline No. of complexes & 11 & 15 & 24 & 21 & 10 & 81 & \\
\hline$\%$ of total & $14 \%$ & $19 \%$ & $30 \%$ & $26 \%$ & $12 \%$ & $100 \%$ & \\
\hline No. of buildings & 57 & 95 & 200 & 117 & 86 & 555 & \\
\hline$\%$ of total & $10 \%$ & $17 \%$ & $36 \%$ & $21 \%$ & $15 \%$ & $100 \%$ & \\
\hline \multicolumn{8}{|l|}{ Scale } \\
\hline Small & $9 \%$ & $9 \%$ & $10 \%$ & $11 \%$ & $1 \%$ & 32 & $40 \%$ \\
\hline Medium & $4 \%$ & $5 \%$ & $7 \%$ & $14 \%$ & $9 \%$ & 31 & $38 \%$ \\
\hline Large & $1 \%$ & $5 \%$ & $12 \%$ & $1 \%$ & $2 \%$ & 18 & $22 \%$ \\
\hline \multicolumn{8}{|l|}{ General form } \\
\hline Shape & $7 \%$ & $12 \%$ & $30 \%$ & $15 \%$ & $12 \%$ & 62 & $77 \%$ \\
\hline Line & $6 \%$ & $6 \%$ & $0 \%$ & $11 \%$ & $0 \%$ & 19 & $23 \%$ \\
\hline
\end{tabular}
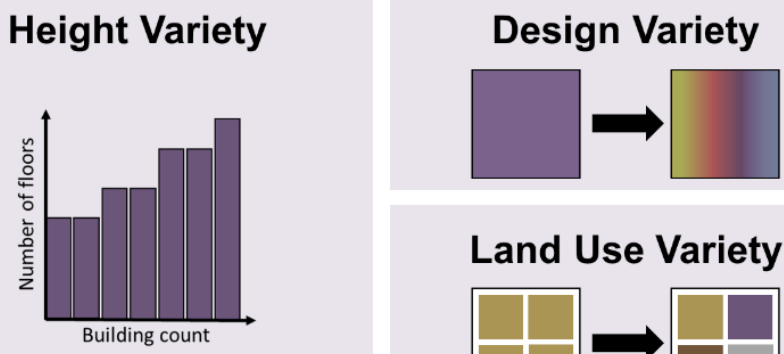

\section{Land Use Variety}

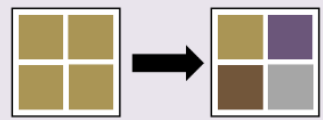

Figure 3. Parameters of the VI. 
between $0.00-1.00)$. The $\mathrm{VI}$ is calculated by the equation:

$$
\mathrm{VI}=\mathrm{vh} * \mathrm{vd} * \mathrm{vl}
$$

producing a range from 0 to 1 . Based on the scores' distribution, the index rates the complex variety as 'low' if the scores are lower than 0.15 , as high if the scores are higher than 0.26 , and as medium if the scores are between 0.16 and 0.25 .

\subsubsection{The Accessibility Index}

The Accessibility Index (Al) refers to the effortlessness of reaching a site, providing a measure that evaluates the relative opportunity for contact or use (Gregory, Jhonson, Pratt, Watts, \& Whatsmore, 2009). Accessibility to parks is defined as one of the major factors influencing green space utilization (Byrne, Wolch, \& Zhang, 2009; Giles-Corti et al., 2005). It combines 4-way intersections around the complex and pedestrian passages (the number of options for getting around and across the complex) as a relatively simple means of operationalizing accessibility. These two indicators (see Figure 4) are calculated as a ratio-the pedestrian passages variable is the count of the pedestrian passages across the complex divided by the number of buildings in the complex (PPR), and the 4-way intersections variable is the number of the 4-way intersections around the complex divided by the number of total intersections around the complex (IR). The Al is calculated using the following equation:

$$
A I=P P R+I R
$$

producing a range from 0 to 2 . Based on the scores' distribution, the index rates the complex accessibility as 'low' if the scores are lower than 0.49 , as 'high' if the scores are higher than 0.8 , and as medium if the scores are between 0.5 and 0.79 .

\subsubsection{The Green-Quality Index}

The Green-Quality Index (GI) discerns and evaluates the quality of the green space as part of the open space of the complex. It is calculated based on three variables: the ratio of the green area to the total area of the complex (gt), the ratio of the green area to the gray area (gg), and the ratio of the permeating green (in which substantial vegetation can grow) to the total green (pg). The GI is based on the separation of 'shades of green' and enables an analysis of the relations between them. Figure 5 describes the diagram of the Gl equation and its parameters. The $\mathrm{Gl}$ is calculated by the equation:

$$
\mathrm{Gl}=(\mathrm{gt} * \mathrm{gg})+\mathrm{pg}
$$

producing a range from 0 to 1.3 . Based on the scores' distribution, the index rates the complex variety as 'low' if
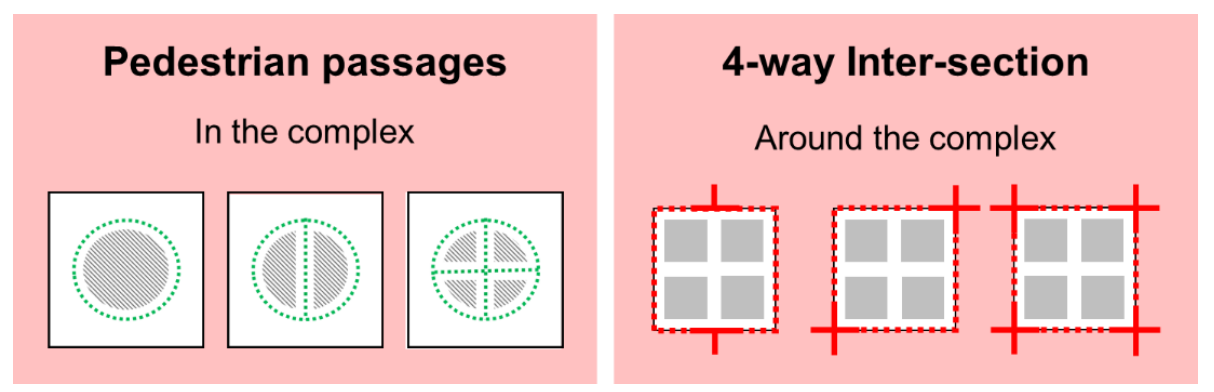

Figure 4. Parameters of the Al.

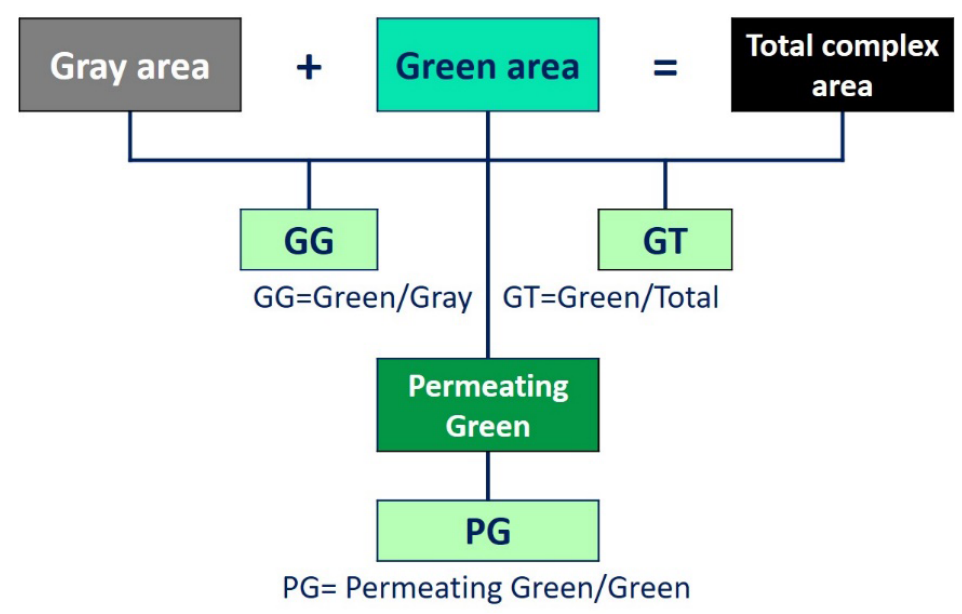

Figure 5. Parameters of the GI. 
the scores are lower than 0.49 , as high if the scores are higher than 0.90 , and as medium if the scores are between 0.50 and 0.89 .

To sum up, the analysis of 81 complexes, summarized in Table 2, suggests that types $C$ and $D$ rank relatively high on the $\mathrm{Gl}$, and types $\mathrm{A}$ (with no designated green) and $B$, to a certain degree, rank very low. These two types ( $A$ and $B$ ) are also low in accessibility ranking whereas type $D$ shows the best accessibility ranking (see Figure 6 ). However, the results are inversed in ranking the design variety; type $B$ presents a relatively high variety of design, type $C$ relatively low, and types $D$ and $E$ present a medium variety level.

\subsection{Green/Gray Nolli Map}

A considerable part of urban morphology research focuses on urban open space and questions how the infrastructure of public space enables and constrains human activity (Gehl \& Svarre, 2013; Huang, 2006; Peters et al., 2010; Skjaeveland \& Garling, 1997). A meaningful measure of green open space further relies on the development of a clear and mappable typology of public space (Dovey \& Pafka, 2014). The familiar black and white nolli map demonstrates the proportion of the built area (colored white) and the unbuilt area (colored black) in the complexes. However, in line with the focus of this article, we propose a gray/green nolli map to capture more and new complexities of the unbuilt area. Thus, the graygreen nolli map represents the non-build open space through 1) a distinction between the gray and green open space, and 2) a distinction between two 'shades of green': 'permeating green' are colored in dark green, and 'non-permeating green' are colored in light green. Figure 7 compares a regular black and white nolli map of seven exemplary HRHCs with the proposed green/gray nolli map of these HRHCs.

Figure 8 graphs the scale and the three evaluation indexes in respect to the green/gray nolli map of seven exemplary HRHCs (types $C, D$, and $E$ ) to suggest a representation of the three outputs together. Such a representation supports the capacity to evaluate each complex and to compare different qualities of the complexes.

\section{Juxtaposing HRHCs Morphology with Users' Experience}

The following qualitative analysis investigates the practices and perspectives of the users of the HRHC open spaces in order to indicate how the morphological outputs are experienced by HRHCs' residents. A major part of the general experience of $\mathrm{HRHC}$ living relates to its scale. The scale of the complex appears to be crucial in residents' experiences of their everyday environment. The scale of the complex was referred to in association with issues of responsibility and control, maintenance of green space, ownership and sense of ownership, sense of community and belonging, and comfort and walkability. In line with Huang's (2006) argument regarding urban open space, residents noted that they favor and usually spend time in the open green space close to their home. As an interviewee (L.Y.) from a medium-scale complex describes: "I don't go to other gardens. I stay with him [her three-year-old boy] only in this garden." The magnitude of these neighborhoods and of each of the buildings is somewhat balanced by the immediacy of the usable open space just downstairs. In the public areas of HRHC neighborhoods, this immediacy and relative intimacy cannot be easily found. The scale of the HRHC and the derived uses of the open green spaces (see Figure 9)

Table 2. Indexes and HRHCs types.

\begin{tabular}{|c|c|c|c|c|c|c|}
\hline \multicolumn{7}{|l|}{ Green Form } \\
\hline Indexes: & A & B & C & D & $\mathbf{E}$ & Total \\
\hline No. of complexes & 11 & 15 & 24 & 21 & 10 & 81 \\
\hline$\%$ from total & $14 \%$ & $19 \%$ & $30 \%$ & $26 \%$ & $12 \%$ & $100 \%$ \\
\hline \multicolumn{7}{|l|}{ Green } \\
\hline Low & $14 \%$ & $6 \%$ & $9 \%$ & $1 \%$ & $1 \%$ & $30 \%$ \\
\hline Medium & $0 \%$ & $9 \%$ & $7 \%$ & $12 \%$ & $6 \%$ & $36 \%$ \\
\hline High & $0 \%$ & $4 \%$ & $14 \%$ & $12 \%$ & $5 \%$ & $35 \%$ \\
\hline \multicolumn{7}{|l|}{ Accessibility } \\
\hline Low & $6 \%$ & $12 \%$ & $9 \%$ & $9 \%$ & $2 \%$ & $38 \%$ \\
\hline Medium & $2 \%$ & $4 \%$ & $12 \%$ & $7 \%$ & $5 \%$ & $31 \%$ \\
\hline High & $5 \%$ & $2 \%$ & $9 \%$ & $10 \%$ & $5 \%$ & $31 \%$ \\
\hline \multicolumn{7}{|l|}{ Variety } \\
\hline Low & $4 \%$ & $4 \%$ & $16 \%$ & $7 \%$ & $6 \%$ & $37 \%$ \\
\hline Medium & $6 \%$ & $4 \%$ & $6 \%$ & $17 \%$ & $5 \%$ & $34 \%$ \\
\hline High & $4 \%$ & $11 \%$ & $7 \%$ & $1 \%$ & $1 \%$ & $25 \%$ \\
\hline
\end{tabular}

Note: Standout low rankings are marked in yellow; standout high rankings in green. 


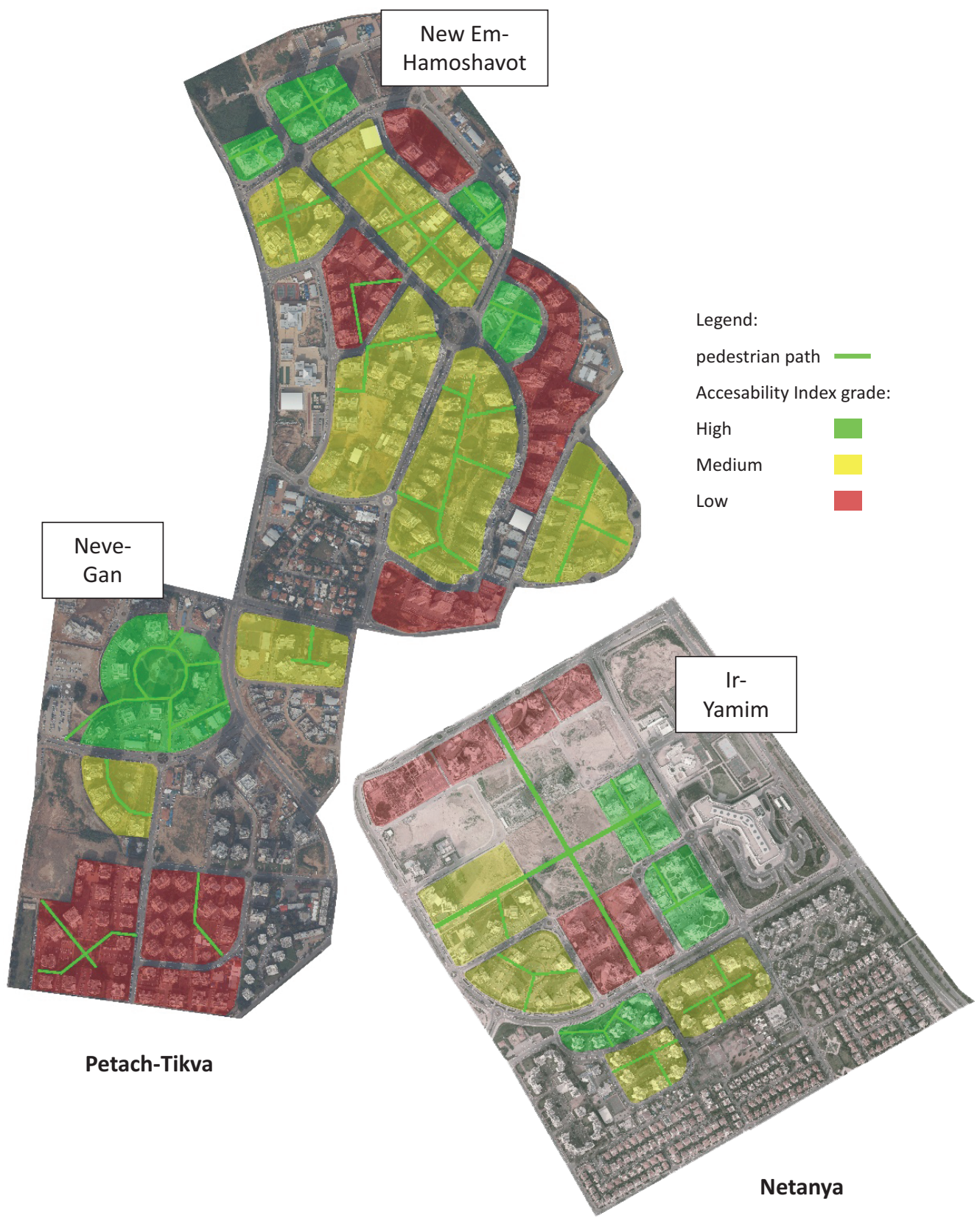

Figure 6. Accessibility scheme of HRHC neighborhoods.

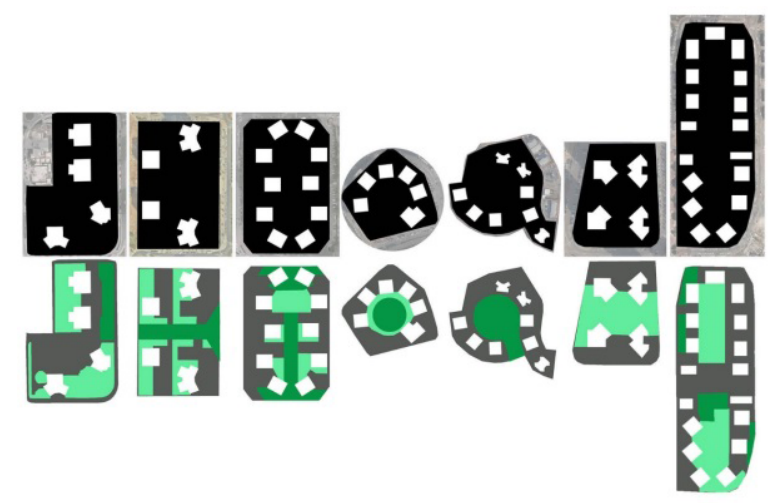

Figure 7. The gray/green nolli map of 7 exemplary complexes. 

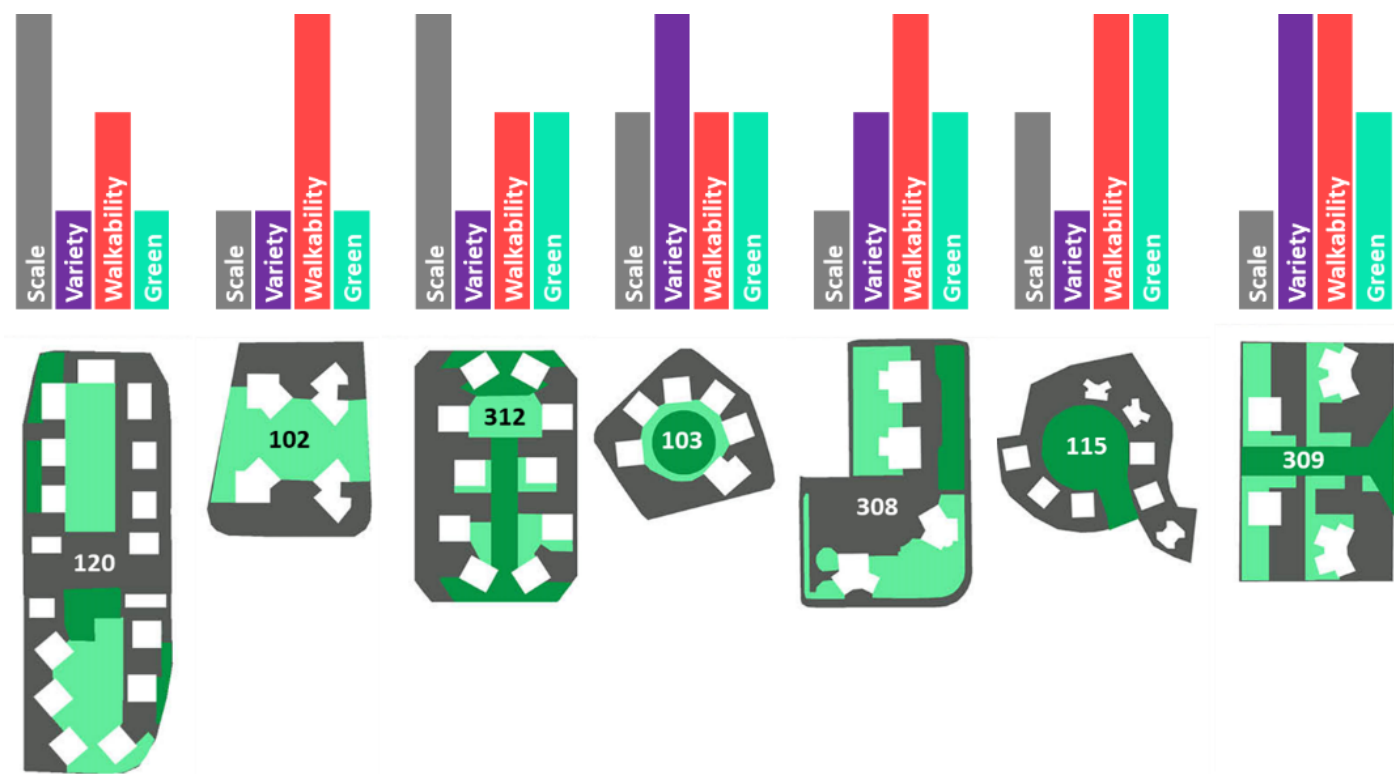

Figure 8. Green/gray nolli maps and the evaluation indexes of seven exemplary complexes.

can produce a very intense experience, as another resident (S.G.) suggests: "On holidays and weekends it's a total nightmare. We hear everything.... Once in a while, when we cannot bear the noise, especially at night, we call the municipal police" (Type C, large-scale).

Since HRHC neighborhoods are relatively new, their public areas offer a higher standard than older neighborhoods. Thus, next to the density created by the HRHCs, these public areas attract outsiders from other parts of the city. This might happen in the center of an HRHC neighborhood or in the center of a type $C$ complex. In both cases, the local residents suffer from the presence of outsiders in different ways:

In the beginning, the fountains worked all the time, and a lot of people from all over the city started to come, it was like a small waterpark for free. There
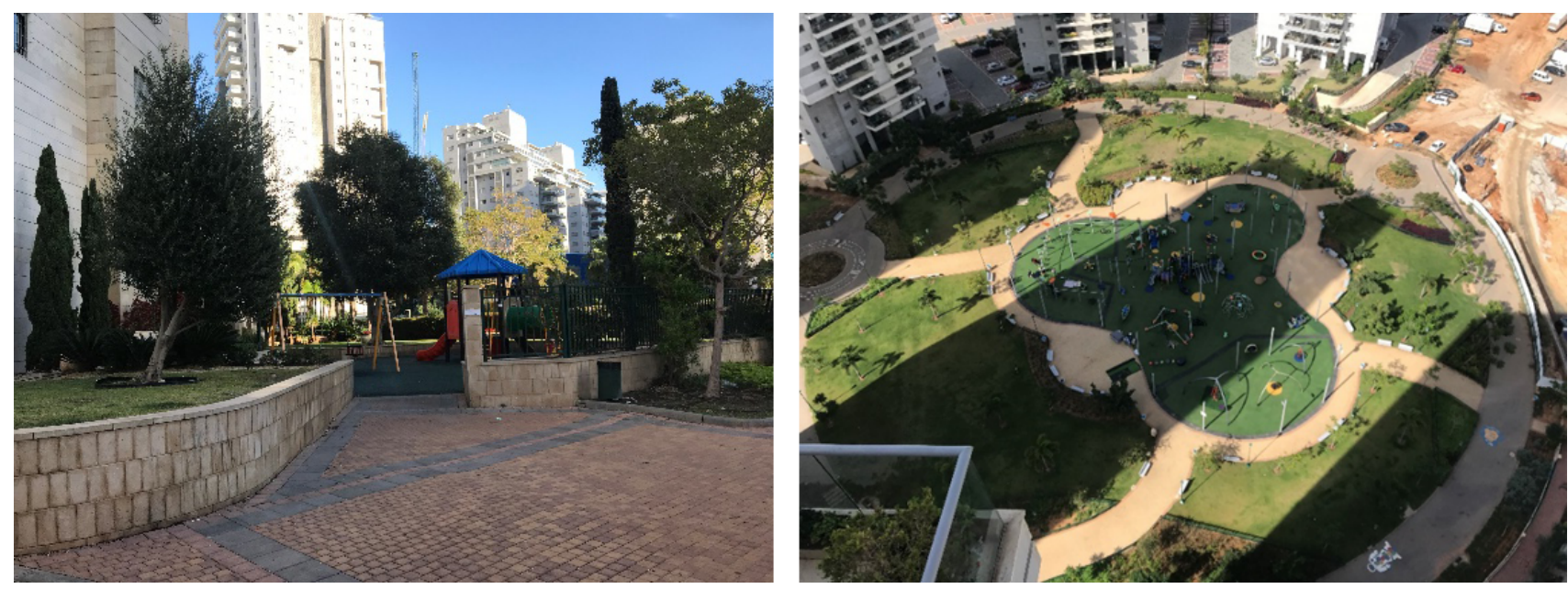

Figure 9. Green spaces of HRHCs. From left to right: small-scale Type C; large-scale Type C. Photographs by author Orly Sasson. 
size complex] is more of a 'playing wild' of all the children. You see it when you come on Saturday morning, after Friday night, it's full of garbage and messy.

The scale of the complex or group of complexes was also juxtaposed by residents with a variety of uses and aesthetics. A mono-used environment (i.e., a complex that is planned for residential use only) often requires an additional large-scale built area for complementary uses, such as commercial or educational uses. Thus, the urban form resulting from a mono-use environment is one that requires residents to engage with large-scale services and commercial centers. This urban form produces a different experience of the space in HRHC; that is, distance, lack of intimacy, and alienation. As one resident (E.L.) suggests: "We miss the grocery store and the greengrocer in Ramat Gan. Here, everything is big" (Type C complex with $\mathrm{VI}=0.56$ ). Another resident (T.Y.) added: "There is no small-scale shopping center around here. In our area, there's no service store one can just go down to buy from and enjoy" (Type $\mathrm{C}$ with $\mathrm{VI}=0.06$ ).

Not only is the experience of the HRHC residents altered by bringing together the parameters of scale and variety of uses, but the daily practices of consumption are also changed under these varying conditions. As another resident (S.G.) explains: "If I had a grocery store here like we used to have under our house, then my consumption would be different. I wouldn't have to plan so much in advance and buy these large amounts of food every time" (Type C complex with VI $=0.13$ ). How she experiences the space where she lives is closely entangled with her daily practices and the different ways that she and other residents inhabit the space and make it their home.

Accessibility is also an important issue that affects residents' experiences of HRHCs. A major part of the problem is that these new neighborhoods in Israel are planned almost exclusively for vehicle use, usually causing traffic jams in rush hours, among other things. However, the emphasis on designing a private vehicleoriented environment is also related to how people move around without a car. Residents of an HRHC neighborhood in Netanya suggest:

The idea of continuous paths is wonderful. It was important for us when we bought the house. (Y.F.)

The planning here is great, there are no roads, it's very friendly to children. (Z.R.)

A resident (T.Y.) from a different neighborhood suggests: "I prefer to go inside the complexes; it's more pleasant, especially because trucks are driving to the construction areas."

However, the Al compiled here demonstrates that in many of the complexes, this aspect receives little attention, and in fact, residents' movement by foot or nonmotor means is channeled to the sidewalks along the road. Even in cases in which the morphological analysis represents the presence of pedestrian trails as part of the $\mathrm{HRHC}$, they are not always accessible or experienced as pleasant for use. A local resident from Neve Gan (R.C.) explains: "The accessibility here is quite bad....I'm not lazy. I usually take a longer stroll just to walk on a better trail." The residents would prefer to consume the space and reorganize it according to their own experiences, feelings, and needs.

These various topological instances, juxtaposed with our morphological analysis, offer a nuanced and encompassing understanding of how present-day urban developments and redevelopments function, what they afford, and how they are experienced by users. By bringing together the more rigid and instrumental analysis of urban morphology with a qualitative analysis of daily practices, perceptions, feelings, and uses, the multiple dimensions of socio-spatial relations in contemporary urban formations are identified.

\section{Conclusion}

The rapid expansion of large urban developments and particularly HRHCs requires additional understanding as well as tools for the examination and evaluation of their forms and capacity to cater to their users' needs. The morphological analysis introduced in this article demonstrates the complex physical data of HRHCs by relatively distinct means to clarify similarities and distinguish between attributes.

In addition, a topological approach towards spatial analyses was introduced in order to address the relational aspects of spaces and places; how they are experienced and produced by the daily practices of users. Ordinary topologies trace the dynamic and daily practices that constitute inhabited space (Harker, 2014). Integrating a qualitative topological approach with topographical analysis encompasses, as we have demonstrated, the multifaceted socio-spatial relations of the vertical space.

Juxtaposing the morphological analysis with a qualitative topological analysis of daily uses, practices, and experiences of HRHCs offers a new understanding of the constitution, consumption, and function of contemporary HRHCs. Moreover, this urban form in general, and its open green spaces in particular, has a broader effect on the city and its dwellers as a whole, not only because people tend to favor being close to home and in familiar urban open spaces (Huang, 2006), but also because of the reconsideration and reallocation of the general green spaces of cities in light of growing urbanization patterns (Kabisch et al., 2015).

This study offers a unique approach and analysis, combining two major tools, i.e., morphological and qualitative topological analyses, to produce a more nuanced understanding of the interconnections between urban forms and users' experiences of these forms. As such, it provides an evaluation scheme to be utilized by plan- 
ners and plans examiners as to the different qualities of the open space and its potential to create a positive experience for its users. For an HRHC neighborhood or a group of complexes in which high-pedestrianism levels and the high use of green spaces (Giles-Corti et al., 2005) is part of the planning goals, the Al may be checked for a minimum required score. Moreover, the scale of a complex may be balanced with types of open spaces. The qualitative analysis suggests that people's experiences of type $D$ complexes (open space in the center) is positive at a small and medium scale, but present different challenges at a large scale (correlation research is needed to sustain this and other insights). Planners may discern the preferred complex type in association to scale considerations that are often formulated based on technical instructions.

While this research offers a new direction for scrutinizing contemporary urban forms, it only takes a first step in examining the vast potential and possibilities offered by HRHC open green spaces. The methodological decision to focus only on the popular types of HRHCS ( $C$ and $D$ types) for the qualitative inquiry limits the discussion on residents' experiences as it pertains to the scale, variety, green-quality, and accessibility of HRHCs to these forms alone. Although we managed to provide insights for practitioners, this direction can and should be further developed. Future research could elaborate on these intersections and the opportunities and challenges they bring about. Moreover, future research would benefit from an in-depth inquiry of the other types of HRHCs as well as from a quantitative inquiry to depict the relations between specific spatial attributes and the feelings, attitudes, and use of residents. Furthermore, applying the three morphological outputs-the typology, the evaluation indexes, and the green/gray nolli mapto HRHCs in other places may help fine-tune, as well as enrich and develop these outputs into a comprehensive tool of studying, assessing, and representing the open spaces of HRHCs.

\section{Acknowledgments}

We are thankful to Prof. Assaf Shwartz and Dr. Tamir Arviv for their contribution in the preliminary stages of the research. Interviews conducted in 2018 and following research was approved by the Technion Ethics Committee (Approval No. 2018-046). In line with the Technion Ethics Committee requirements consent was obtained for all participants in the research.

\section{Conflict of Interests}

The authors declare no conflict of interests.

\section{References}

Alterman, R. (2010). The maintenance of residential towers in condominium tenure: A comparative analysis of two extremes-Israel and Florida. In S. Blandy, A. Dupuis, \& J. Dixon (Eds.), Multi-owned housing: Law, power, and practice (pp. 126-142). Farnham: Ashgate.

Aviv, D., Yaacobi, D., Noiman, B., Coppell, D., Robinson, D., Revisin, N., \& Shlush, T. (2018). High-rise construction: Policy Paper [Mismach Mediniyut: Bnia La-Gova]. Tel-Aviv: Alrov Institute for Real Estate Research.

Baxter, R. (2017). The high-rise home: Verticality as practice in London. International Journal of Urban and Regional Research, 41(2), 334-352.

Brumann, C. (2012). Re-uniting a divided city: High-rises, conflict and urban space in central Kyoto. In E. Schulz (Ed.), Urban Spaces in Japan (pp. 67-87). London: Routledge.

Byrne, J., Wolch, J., \& Zhang, J. (2009). Planning for environmental justice in an urban national park. Journal of Environmental Planning and Management, 52(3), 365-392.

Creswell, J. (1998). Qualitative inquiry and research design: Choosing among five traditions. California: Sage.

Dovey, K., \& Pafka, E. (2014). The urban density assemblage: Modelling multiple measures. Urban Design International, 19(1), 66-76.

Drozdz, M., Appert, M., \& Harris, A. (2018). High-rise urbanism in contemporary Europe. Built Environment, 43(4), 469-480.

Eizenberg, E., \& Shilon, M. (2016). Pedagogy for the new planner: Refining the qualitative toolbox. Environment and Planning B: Planning and Design, 43(6), 1118-1135.

Evans, J., \& Jones, P. (2011). The walking interview: Methodology, mobility and place. Applied Geography, 31(2), 849-858.

Fincher, R. (2007). Is high-rise housing innovative? Developers' contradictory narratives of high-rise housing in Melbourne. Urban Studies, 44(3), 631-649.

Gandy, M. (2003). Concrete and clay: Reworking nature in New York City. Cambridge, MA: MIT Press.

Gehl, J. (2011). Life between buildings: Using public space. Washington, DC: Island Press.

Gehl, J., \& Svarre, B. (2013). How to study public life. Washington, DC: Island Press.

Giles-Corti, B., Broomhall, M. H., Knuiman, M., Collins, C., Douglas, K., Ng, K., Lange, A., \& Donovan, R. J. (2005). Increasing walking: How important is distance to, attractiveness, and size of public open space? American Journal of Preventive Medicine, 28(2), 169-176.

Graham, S., \& Hewitt, L. (2012). Getting off the ground: On the politics of urban verticality. Progress in $\mathrm{Hu}$ man Geography, 37(1), 72-92.

Gregory, D., Jhonson, R., Pratt, G., Watts, M. J., \& Whatsmore, S. (2009). The Dictionary of human geography (5th ed.). Hoboken, NJ: Wiley-Blackwell.

Hall, T., \& Sanders, P. (2011). Morphological design control for large-scale city development: A new proposal. 
Built Environment, 37(4), 427-444.

Harker, C. (2014). The only way is up? Ordinary topologies of Ramallah. International Journal of Urban and Regional Research, 38(1), 318-335.

Harris, A. (2015). Vertical urbanisms: Opening up geographies of the three-dimensional city. Progress in $\mathrm{Hu}$ man Geography, 39(5), 601-620.

Hartig, T. (1993). Nature experience in transactional perspective. Landscape and Urban Planning, 25(1/2), 17-36.

Huang, S. C. L. (2006). A study of outdoor interactional spaces in high-rise housing. Landscape and urban planning, 78(3), 193-204.

Jabareen, Y. R. (2006). Sustainable urban forms: Their typologies, models, and concepts. Journal of Planning Education and Research, 26(1), 38-52.

Jackson, L. (2003). The relationship of urban design to human health and condition. Landscape and Urban Planning, 64(4), 191-200.

Kabisch, N., Qureshi, S., \& Haase, D. (2015). Humanenvironment interactions in urban green spaces: A systematic review of contemporary issues and prospects for future research. Environmental Impact Assessment Review, 50, 25-34.

Kaplan, S. (1995). The restorative benefits of nature: Toward an integrative framework. Journal of environmental psychology, 15(3), 169-182.

Kropf, K. (2018). The handbook of urban morphology. Chichester: John Wiley \& Sons.

Lacoeuilhe, A., Prévot, A. C., \& Shwartz, A. (2017). The social value of conservation initiatives in the workplace. Landscape and Urban Planning, 157, 493-501.

Lowry, G. \& McCann, E. (2011). Asia in the mix: Urban form and global mobilities-Hong Kong, Vancouver, Dubai. In A. Ong \& A. Roy (Eds.), Worlding cities: Asian experiments and the art of being global (pp. 182-204). Oxford: Blackwell.

McFarlane, C. (2011). The city as assemblage: Dwelling and urban space. Environment and Planning D: Society and Space, 29(4), 649-671.

Miller, J. R. (2005). Biodiversity conservation and the ex- tinction of experience. Trends in Ecology and Evolution, 20(8), 430-434.

Nethercote, M. (2018). Theorising vertical urbanisation. City, 22(5/6), 657-684.

Patricios, N. N. (2002). Urban design principles of the original neighbourhood concepts. Urban Morphology, 6(1), 21-36.

Peters, K., Elands, B., \& Buijs, A. (2010). Social interactions in urban parks. Urban Forestry \& Urban Greening, 9(2), 93-100.

Pont, M. B., \& Haupt, P. (2010). Spacematrix: Space, density and urban form. Rotterdam: NAi Publishers.

Pyle, R. M. (1978). The extinction of experience. Horticulture, 56, 64-67.

Rode, P., Keim, C., Robazza, G., Viejo, P., \& Schofield, J. (2014). Cities and energy: Urban morphology and residential heat-energy demand. Environment and Planning B: Planning and Design, 41(1), 138-162.

Shwartz, A., Pett, T. J., Irvine, K. N., Dallimer, M., \& Davies, Z. G. (2016). Unpacking the people-biodiversity paradox: A conceptual framework. BioScience, 66(7), 576-583.

Skjaeveland, O., \& Garling, T. (1997). Effects of interactional space on neighbouring. Journal of Environmental Psychology, 17(3), 181-198.

Soga, M., \& Gaston, K. J. (2016). Extinction of experience: The loss of human-nature interactions. Frontiers in Ecology and the Environment, 14(2), 94-101.

Turkington, R., van Kempen, R., \& Wassenberg, F. (2004). High-rise housing in Europe: Current trends and prospects. Housing and Urban Policy Studies, 28, $1-28$.

Whitehand, J., \& Gu, K. (2007). Urban conservation in China: Historical development, current practice and morphological approach. Town Planning Review, 78(5), 643-670.

Winston, N. (2017). Multifamily housing and resident life satisfaction in Europe: An exploratory analysis. Housing Studies, 32(7), 887-911.

Yuen, B., \& Yeh, A. G. (Eds.). (2011). High-rise living in Asian cities. New York, NY: Springer.

\section{About the Authors}

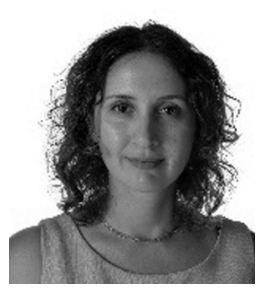

Efrat Eizenberg, PhD in Environmental Psychology, is an Associate Professor at the Faculty of Architecture and Town Planning at the Technion, Israel. Her research topics include urban regeneration and development, urban open spaces, planning with communities, and planning research methodologies. She is the author of From the Ground Up: Community Gardens in New York City and the Politics of Spatial Transformation, published in 2013 by Routledge.

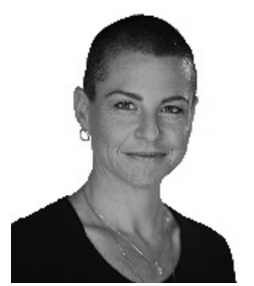

Orly Sasson is an MA student in Urban Planning at the Technion-Israel Institute of Technology. Orly is a trained landscape architect with professional planning experience both in private companies and public service. The present article is based on her thesis which discusses the role of these green spaces in the experience of residents and proposing a set of parameters with which to discern and evaluate various characteristics of the green spaces of high-rise residential complexes based on morphological analysis. 


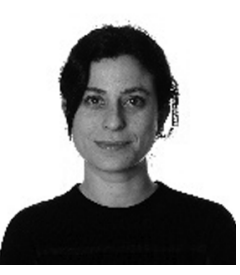

Mor Shilon is a Postdoctoral Fellow at the Technion-Israel Institute of Technology. Mor is a trained sociologist and an urban planner specialized in the sociology of space, technology and innovation, and qualitative research methods. In her research, she combines relational approaches and qualitative methodologies with urban planning theories to re-consider the implications and engagements of technology in the generation of socio-spatial environments. She has published articles in scholarly journals reflecting her interest in the interface of urban planning, more-than-human theories, and qualitative research methods. 